\title{
Setup of standard PD calibrator and its uncertainties
}

\author{
Kwang-Hwa Kim ${ }^{\dagger}$, Sang-Hwa Yi*, Heun-Jin Lee* and Dong-Sik Kang*
}

\begin{abstract}
The present paper describes the setup of standard partial discharge calibrator for measuring partial discharge and estimating uncertainties. The standard PD calibrator was designed and set up, consisting of a digital pulse generator, capacitor modules, and a digital oscilloscope controlled by software developed in the laboratory. Using this software, averages of charges and rising times and their standard deviations in the measured pulses can also be calculated. The standard PD calibrator generates five types of pulses: single, double, random, oscillating, and long-rising. The coefficient sensitivities to estimate the uncertainties of pulses were extracted in the model circuit of the standard PD calibrator. The uncertainties of charges and rising times in pulses of the standard PD calibrator were estimated with single pulses. These values were $0.3 \%-1.4 \%$ in charges and $1.9 \%-7.0 \%$ in rising time; however, these values are lower than the limit values in IEC 60270.
\end{abstract}

Keywords: Partial discharge, Uncertainties, Charge, Pulses, Calibrator

\section{Introduction}

In the industrial society, supply of electric power is very important. Technologies to design, test, and produce electric power apparatus have been developed to increase the reliability of power supply.

The partial discharge (PD) test, which is conducted after producing or repairing an electric power apparatus, increases its reliability. Because of high electric field at the interface between solid and gas or liquid insulation, the occurrence of PD rapidly breaks down the insulation systems of compactelectric power apparatus. The limit level of PD has been lowered and regulated in the standard specifications related to PD [1-4]. Because electric power apparatus need to be highly reliable and the expense for maintenance must be cheap, PD technology to diagnose the conditions of such apparatus has been of utmost importance.

The limit level of PD in electric power apparatus has been lowered. Thus, accuracy has to be increased and uncertainty has to be decreased in the measurement of PD. Because the uncertainties of the PD calibrator for measuring PD in transformers and circuit breakers are regulated, the setting up of systems for calibrating and sustaining PD calibrators is crucial. Such a system needs a standard PD calibrator that can trace the uncertainties of its components and estimate the expanded uncertainties [510]. When uncertainties of the general PD calibrator are estimated, setting up the standard PD calibrator is necessary to increase competitiveness of domestic electric

$\dagger \quad$ Corresponding Author: Power Facility Diagnosis Research Center, Korea Electrotechnology Research Institute (khkim124@keri.re.kr)

* Power Facility Diagnosis Research Center, Korea Electrotechnology Research Institute (khkim124@keri.re.kr)

Received: August 10, 2010; Accepted: June 9, 2011 industry.

Therefore, the present paper describes the setup and design of a standard PD calibrator consisted of a pulse generator, capacitor modules, and a digital oscilloscope. The software to generate calibration pulse and calculate the uncertainties of pulses in the standard PD calibrator is developed, and uncertainty characteristics of this calibrator are shown.

\section{Setup of the standard PD calibrator}

\subsection{Characteristics of the PD calibrator in IEC 60270}

The standard PD test method in the IEC 60270 is the coupling capacitor method [3]. When this method is used, the charges of partial discharge are usually determined with peak magnitudes of pulses in the PD detector. Peaks of pulses in the PD detector depend on the capacitances of the specimens and the measuring circuit. When the detected PD pulses are compared with the calibration pulses, the charges of PD can be measured. Because the PD calibrator needs a given pulse wave and wider frequency bandwidth than the PD detector, its characteristics are checked periodically. IEC 60270 regulates the specification to estimate the PD calibrator, and this specification is shown in Table 1.

This standard specification regulates the type test, routine test, performance test, and performance check of the PD calibrator. Charge, rising time, and repetition rate of pulse must be measured and calibrated in these tests, except for the performance check. 
Table 1. Uncertainties of the PD calibrator in IEC 60270

\begin{tabular}{c|c|c|c}
\hline & Items & $\begin{array}{c}\text { Uncertainty } \\
\text { requirement }\end{array}$ & \multirow{2}{*}{ Note } \\
\cline { 2 - 3 } $\begin{array}{c}\text { Calibrator } \\
\text { uncertainty }\end{array}$ & $\begin{array}{c}\text { Calibrator charge } \\
\left(\mathrm{q}_{0}\right)\end{array}$ & $\pm 5 \%$ or $\leq 1 \mathrm{pC}$ & \multirow{2}{*}{ IEC 60270 } \\
\cline { 2 - 3 } & $\begin{array}{c}\text { Pulse rising time } \\
\left(\mathrm{t}_{\mathrm{r}}\right)\end{array}$ & $\pm 10 \%(\leq 60 \mathrm{~ns})$ & Clause 7.2.3 \\
\cline { 2 - 3 } & $\begin{array}{c}\text { Pulse repetition } \\
\text { rate }(\mathrm{N})\end{array}$ & $\pm 1 \%$ & \\
\hline
\end{tabular}

\subsection{The characteristics of the standard PD calibrator}

PICOR (programmable impulse charge calibrator: standard PD calibrator), which was developed in PTB (Physikalisch Technische Bundesan-stalt), Germany, is the standard PD calibrator. PICOR consists of a digital-toanalog (DA) converter, a digital oscilloscope, and modules. Because the DA converter has a $50 \mathrm{Ms} / \mathrm{s}$ sampling rate, it generates pulses that have no controllable duration time. When the pulse is measured with a digital oscilloscope, the value is read by the human eye. PICOR has characteristic uncertainties (Table 2), which have been confirmed through comparison tests performed by research institutes, universities, and industries in Europe [5, 6].

The parameters of pulses in Table 2 are different from those in Table 1 of IEC 60270; however, the characteristics of these parameters are same. The rising time of pulse in IEC 60270 reflects the duration and upper limit frequency in Table 2. The uncertainty requirements of the standard PD calibrator require the value in Table 1 in the rising time and the value in Table 2 in the charge.

\subsection{Design of the standard PD calibrator system}

The standard PD calibrator consists of a pulse generator, capacitor modules, a charge measuring device, and software to control its system and process the measuring data. Its concept design is shown in Fig. 1. A digital programmable pulse generator (Agilent 81150A) that can generate various types of pulses was selected for the calibrator [11].

Table 2. Uncertainties of PICOR

\begin{tabular}{c|c|c|c}
\hline & Items & $\begin{array}{c}\text { Uncertainty } \\
\text { requirement }\end{array}$ & Note \\
\cline { 2 - 3 } & $\begin{array}{c}\text { Calibrator charge } \\
\left(\mathrm{q}_{0}\right)\end{array}$ & $\pm(0.1 \mathrm{pC}+0.03 \mathrm{q})$ & \\
\cline { 2 - 3 } uncertainty & $\begin{array}{c}\text { Pulse duration } \\
\left(\mathrm{t}_{\mathrm{d}}\right)\end{array}$ & $\pm 10 \%$ & $\begin{array}{c}\text { q is charge: } \\
1-500(\mathrm{pC})\end{array}$ \\
\cline { 2 - 3 } & $\begin{array}{c}\text { Upper frequency } \\
\text { limit }\end{array}$ & - & \\
\hline
\end{tabular}

The charge-measuring device used was a digital oscilloscope with high resolution and high-speed sampling
(Tektronix DPO7254) [12]. Its characteristics are shown in Table 3. The ranges of charges are controlled by capacitor modules, which have 1,10 , and $50 \mathrm{pF}[13,14]$. The software that controls the system and processes the measuring data was developed using Visual Basic and Chart FX.

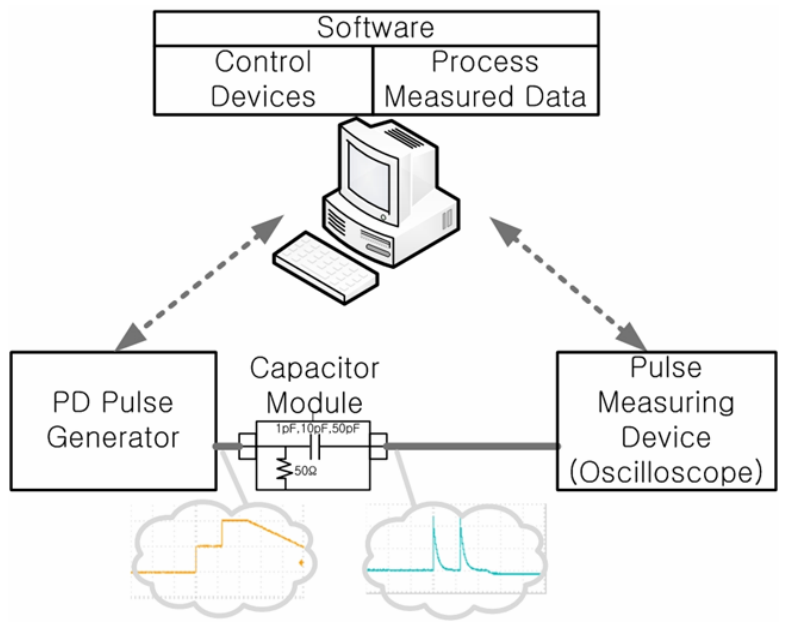

Fig. 1. Concept design of the standard PD calibrator

Table 3. Characteristics of the standard PD calibrator

\begin{tabular}{|c|c|c|c|}
\hline Part & $\begin{array}{l}\text { Digital pulse generator } \\
\text { (Agilent } 81150 \mathrm{~A} \text { ) }\end{array}$ & $\begin{array}{l}\text { Capacitor } \\
\text { modules }\end{array}$ & $\begin{array}{l}\text { Charge measuring device } \\
\text { (Tektronix DPO7254) }\end{array}$ \\
\hline $\begin{array}{l}\text { Characteri } \\
\text { stics }\end{array}$ & $\begin{array}{c}\text { 14-bit DAC (digital-to- } \\
\text { analog converter) } \\
\text { Sample rate: } 2 \mathrm{GS} / \mathrm{s} \\
\text { Waveform memory: } \\
512 \mathrm{kSa} \\
\text { Maximum amplitude } \\
\text { voltage: } 10 \mathrm{~V}\end{array}$ & $\begin{array}{l}1 \mathrm{pF}(\mathrm{A} 1) \\
10 \mathrm{pF}(\mathrm{A} 2) \\
50 \mathrm{pF} \text { (A3) }\end{array}$ & $\begin{array}{l}\text { Digital oscilloscope } \\
\text { Bandwidth: } 2.5 \mathrm{GHz} \\
\text { Sample rate: } 40 \mathrm{GS} / \mathrm{s} \\
\text { Vertical resolution: } \\
\text { single } 8 \text { bit, } \\
\text { average } 11 \text { bit }\end{array}$ \\
\hline
\end{tabular}

*The inner characters of () are names of the modules.

\subsection{Standard PD calibrator system}

The standard PD calibrator utilizing the concept design of Fig. 1 is shown in Fig. 2. Fig. 2(a) shows the hardware of the standard PD calibrator. Fig. 2(b) shows the software that controls the pulse generator and thatautomatically processes the measuring data. With this software, the type of pulse can be selected, and the pulse parameters to control the shape, magnitude, and repetition rate of pulse can be determined. The software is able to automatically calculate averages of charges and rising times, as well as the standard deviations, related to uncertainties from measuring data. Moreover, to increase accuracy of measurement, the software has the ability to eliminate the errors of the human eye and offset voltages included in measuring data using integrating method. This is the novel system to be controlled and processed by the software using the networking method. 


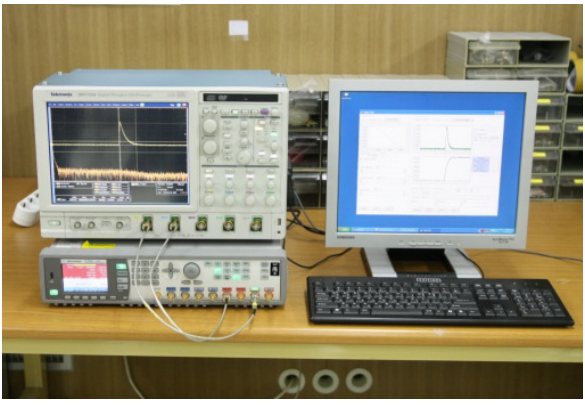

(a) Photo of the standard PD calibrator

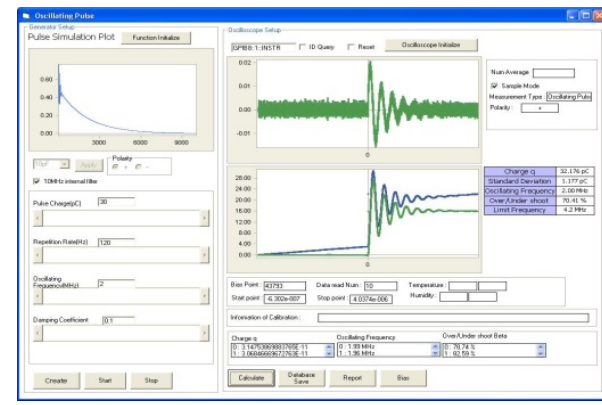

Controlling part Processing part

(b) The software to generate and measure pulses in the standard PD calibrator

Fig. 2. Standard PD calibrator

Fig. 3 shows calibration pulses generated by this calibrator. The types of pulses are single, double, random, oscillating, and long-rising. Fig. 3(a) shows single pulses that have the same charge magnitude $(20 \mathrm{pC})$ and different durations. Fig. 3(b) shows double pulses that have $1 \mu \mathrm{s}$ interval time between two pulses. Fig. 3(c) shows random pulses that have a sequence of six pulses and $20 \mu$ s interval time between pulses. Fig. 3(d) shows an oscillating pulse that has $1 \mathrm{MHz}$ oscillating frequency and 0.1 damping coefficient. Fig. 3(e) shows long-rising pulses that have the same charge magnitude $(20 \mathrm{pC})$ and different rising time.

Table 4 shows characteristics of these pulse, as well as the controllable terms and ranges of the calibration pulses. Charge, duration time, and repetition rate of pulse are the adjustable terms of the single pulse. The adjustable terms of the double pulse are same as those of single pulse with an interval between two pulses. The adjustable terms of the random pulse are charge, repetition rate, interval time, and sequence of pulses. This pulse can be synchronized with power frequency phase. The adjustable terms of the oscillating pulse are charge, repetition rate, oscillating frequency, and damping coefficient. The adjustable terms of the long-rising pulse are charge, repetition rate, and rising time. These pulses can be used in estimating the characteristic of the PD detector.

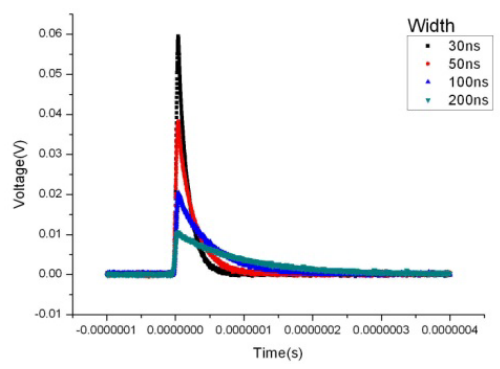

(a) Single pulse (charge: $20 \mathrm{pC}$ )

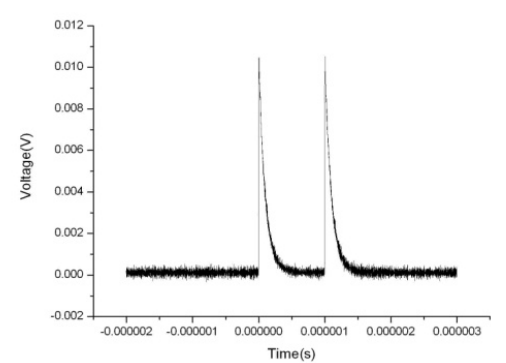

(b) Double pulse (charge $10 \mathrm{pC}$, interval time $1 \mu \mathrm{s}$ )

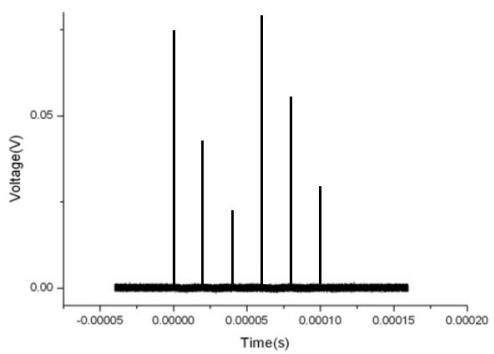

(c) Random pulse (6 pulses, interval time $20 \mu \mathrm{s}$ )

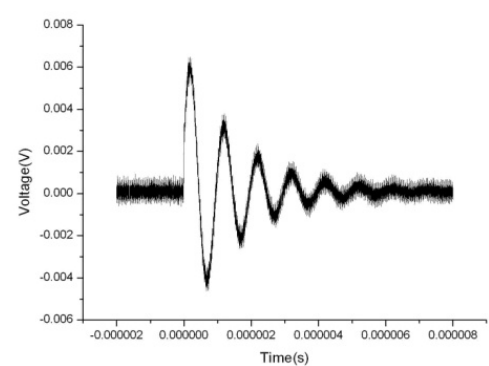

(d) Oscillating pulse (charge $20 \mathrm{pC}$, frequency $1 \mathrm{MHz}$, damping coefficient 0.1 )

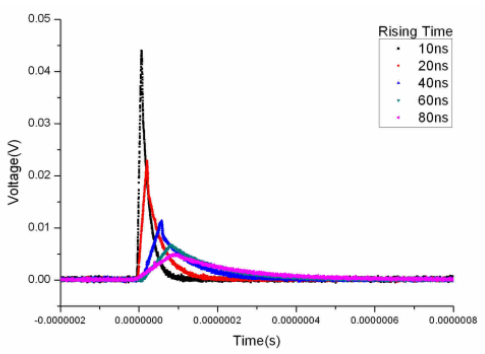

(e) Long-rising pulse (charge $20 \mathrm{pC}$ )

Fig. 3. Pulses in the standard PD calibrator 
Table 4. Characteristics of pulses in the standard PD calibrator

\begin{tabular}{|c|c|c|c|c|c|c|c|}
\hline \multirow[b]{2}{*}{ Pulse shape } & \multicolumn{6}{|c|}{ Specification } & \multirow[b]{2}{*}{ Remark } \\
\hline & $\begin{array}{c}\text { Charge } \\
(\mathrm{pC})\end{array}$ & $\begin{array}{l}\text { Duration } \\
\text { (ns) }\end{array}$ & $\begin{array}{l}\text { Rising } \\
\text { time (ns) }\end{array}$ & $\begin{array}{l}\text { Repetition } \\
\text { rates }(\mathrm{Hz})\end{array}$ & Interval ( $\mu \mathrm{s})$ & Others & \\
\hline Single pulse & $0-500$ & $10-500$ & $<5$ & $1-650$ & & & \\
\hline Double pulse & $0-250$ & $10-350$ & $<5$ & $1-650$ & $1-30$ & & \\
\hline Random pulse & $0-500$ & $50-60$ & $<10$ & 100,120 & $20-100$ & $\begin{array}{c}\text { No. of pulses: } \\
3-10\end{array}$ & $\begin{array}{c}\text { Phase } \\
\text { triggering }\end{array}$ \\
\hline $\begin{array}{l}\text { Oscillating } \\
\text { pulse }\end{array}$ & $0-250$ & & - & $1-650$ & & $\begin{array}{c}\text { Oscillating } \\
\text { frequency: } \\
0.5-8 \mathrm{MHz} \\
\text { Damping } \\
\text { coefficient: } \\
0.01-0.25\end{array}$ & \\
\hline $\begin{array}{l}\text { Long-rising } \\
\text { pulse }\end{array}$ & $0-500$ & $\underset{(5-6)}{\text { Rising time }} \times$ & $\begin{array}{l}10,20,30,40 \\
50,60,80,100\end{array}$ & $1-650$ & & & \\
\hline
\end{tabular}

\section{Measurement of characteristics and estimation of uncertainties in PD calibrator}

\subsection{Charge, rising time, and repetition rate of pulses in $P D$ calibrator}

In IEC 60270, the reference method is recommended for comparing the standard (reference) PD calibrator with the tested calibrator in the PD measurement circuit. In contrast, the alternative method is recommended for measuring output pulses of the calibrator with measuring resistor and digital oscilloscope.

The former method is complex because this method requires a standard $\mathrm{PD}$ calibrator, a $\mathrm{PD}$ detector, and a $\mathrm{PD}$ measurement circuit. The latter method is a simple one, using only a digital oscilloscope; however, a program that can calculate the charge from measuring pulse data is also needed [1]. In the present paper, the latter method is used. The measuring circuit is shown in Fig. 4.

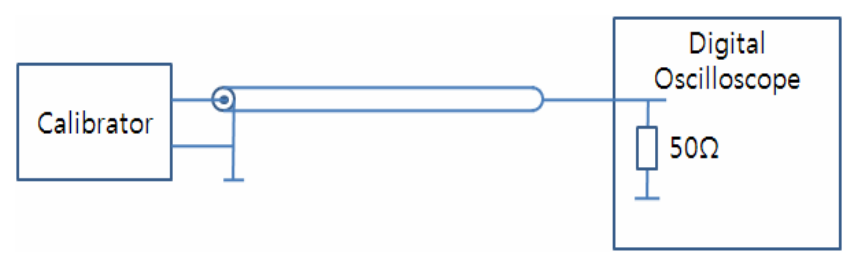

Fig. 4. Alternative method to estimate the PD calibrator

To estimate the characteristics of the PD calibrator, its pulse is applied to the resistor and charge of pulse is estimated, as in (1), by integrating the voltage across resistor. Methods to integrate voltage are shown in Table 5. Method 1(b) is used in this paper. However, PICOR uses Method 1(a). The developed software automatically calculates charge, rising time, duration, and their average values and standard deviations:

$$
q=\frac{1}{R} \int v(t) \cdot d t
$$

where $\mathrm{v}(\mathrm{t})$ is the voltage drop of the resistor, which is measured with a digital oscilloscope.

The rising time of the pulses, $t r$, is defined as the time interval between the point at $10 \%$ and $90 \%$ of the front in voltage signal across the measuring resistor $R=50 \Omega$ of Fig. 4. The duration of the pulses, $t d$, is defined as the time interval between $10 \%$ at the front and $10 \%$ at the tail of the voltage signal.

Table 5. Software to calculate charge from the voltage drop of the resistor

\begin{tabular}{c|c}
\hline Method & Calculating method \\
\hline Method 1(a) & Internal integration software of the recorder \\
\hline Method 1(b) & Software developed by laboratory \\
\hline Method 1(c) & PC Excel software \\
\hline
\end{tabular}

\subsection{Uncertainties of the PD calibrator}

To consider uncertainties of the PD calibrator, the parameters that affect uncertainties must first be analyzed, and a model circuit to theoretically estimate these parameters is required [4]. The model circuit, which consists of a pulse generator, a capacitor module, and a measuring digital oscilloscope, is shown in Fig. 5.

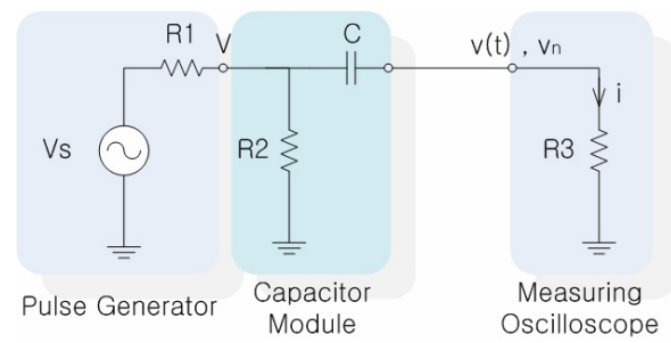

Fig. 5. Circuit diagram of the PD calibrator

As Fig. 5 shows, $V s$ is the source voltage of the pulse generator; $V$ is the output voltage of the pulse generator; 
$R 1$ is the output impedance of the pulse generator; $R 2$ is the load impedance of the module; $C$ is the coupling capacitance of the module; $R 3$ is the input impedance of the measuring oscilloscope; $i$ is the current of $R 3, v(t)$; and $v_{n}$ is the voltage across $R 3$.

In Fig. 5, the charge of pulses integrates the current across $R 3$, which is calculated similarly to (2). When this equation is integrated, the result is the same value of capacitor charge. Therefore, the charge can be expressed as (3).

$$
\begin{aligned}
& q=\int i \cdot d t \\
& q=V \cdot C
\end{aligned}
$$

Because the current $i$ of (2) is measured from the voltage across $R 3$ resistor, the calculation of charge in the digital oscilloscope is expressed in (4):

$$
q=\sum_{n=1}^{N} \frac{v_{n}}{R 3} \Delta T
$$

where $v_{n}$ is the voltage value in $\mathrm{n}$ sample and $\Delta T$ is the interval time between samples.

The estimation of uncertainties in the standard PD calibrator requires sensitive coefficients and standard uncertainties of components. The model circuit in Fig. 4 consists of passive components; however, the pulse generator and the digital oscilloscope are complex electronic devices. The uncertainties of their parameters, as suggested by the makers of these devices, can be used in acquiring the expanded uncertainties of the standard PD calibrator [11-14]. Therefore (5) and (6) are sensitive coefficients of resistor and capacitor, respectively, in the module.

$$
\begin{gathered}
c_{r 2}=\frac{\partial q}{\partial R 2}=\frac{V \cdot C}{(R 1+R 2)}\left(1-\frac{R 2}{R 1+R 2}\right) \\
c_{c}=\frac{\partial q}{\partial C}=\frac{R 2 \cdot V}{(R 1+R 2)}
\end{gathered}
$$

The above sensitive coefficients and the standard uncertainties of the resistor, capacitor, pulse generator, and oscilloscope are needed to calculate the combined standard uncertainty, which is given in (7). The effective degrees of freedom needed to calculate expanded uncertainties can be acquired from (8). Moreover, the coverage factor can be acquired from the effective degrees of freedom. The expanded uncertainty is the product of the combined standard uncertainty and the coverage factor.

$$
u_{c}=\sqrt{\sum\left(c_{i} u\left(x_{i}\right)\right)^{2}}
$$

$$
\gamma_{\mathrm{eff}}=u_{c}^{4} / \sum_{i=1}^{n} \frac{\left|c_{i} u\left(x_{i}\right)\right|^{4}}{\gamma_{i}}
$$

where $c_{i}$ is the sensitive coefficient, $u\left(x_{i}\right)$ is the standard uncertainty, and $\gamma_{i}$ is the degree of freedom.

To acquire the uncertainty of the standard PD calibrator, the standard uncertainties and degrees of freedom in the components of the PD calibrator have to be analyzed. The components of the pulse generator are rounding-off, offset, and amplitude accuracy of the output voltages. The components of the measuring digital oscilloscope are the DC accuracy and the clock accuracy of the measuring data. The components of the capacitor modules are the values of capacitors and resistors and their temperature coefficients. Table 6 shows the standard uncertainties, types, and degrees of freedom in the components of the standard PD

\begin{tabular}{|c|c|c|c|c|}
\hline Part & Component & $\begin{array}{c}\left|\mathrm{c}_{\mathrm{i}} \mathrm{u}\left(\mathrm{x}_{\mathrm{i}}\right)\right| \\
(\mathrm{pC})\end{array}$ & Type B & $\gamma_{\mathrm{i}}$ \\
\hline \multirow{3}{*}{$\begin{array}{c}\text { Pulse } \\
\text { generator } \\
\text { (sources) }\end{array}$} & Rounding off & $2.89 \times 10^{-4} \mathrm{C}$ & Excellent & 1000 \\
\hline & Offset $(0 \mathrm{~V})$ & $5 \times 10^{-4} \mathrm{C}$ & Reasonable & 8 \\
\hline & $\begin{array}{l}\text { Amplitude } \\
\text { accuracy }\end{array}$ & $4 \times 10^{-4} \mathrm{VC}$ & Reasonable & 8 \\
\hline \multirow{2}{*}{$\mathrm{R} 2$} & Value & $\begin{array}{c}2.5 \times 10^{-4} \\
\mathrm{VC}\end{array}$ & & 20 \\
\hline & $\begin{array}{c}\text { Absolute } \\
\text { temperature }\end{array}$ & $\begin{array}{r}7.23 \times 10^{-6} \mid \\
\mathrm{T}-20 \mid \mathrm{VC}\end{array}$ & Reasonable & 8 \\
\hline \multirow{4}{*}{$\mathrm{C}$} & Value of $1 \mathrm{pF}$ & $3 \times 10^{-3} \mathrm{~V}$ & & 20 \\
\hline & Value of $10 \mathrm{pF}$ & $5.5 \times 10^{-3} \mathrm{~V}$ & & 20 \\
\hline & Value of $50 \mathrm{pF}$ & $2.55 \times 10^{-2} \mathrm{~V}$ & & 20 \\
\hline & $\begin{array}{c}\text { Temperature } \\
\text { characteristics }\end{array}$ & $\begin{array}{c}1.73 \times 10^{-5} \mid \\
\mathrm{T}-20 \mid \mathrm{VC}\end{array}$ & Reasonable & 8 \\
\hline \multirow{2}{*}{$\begin{array}{c}\text { Digital } \\
\text { oscilloscope }\end{array}$} & $\begin{array}{c}\text { DC accuracy } \\
(10 \mathrm{mV})\end{array}$ & $1.25 \times 10^{-3} \mathrm{q}$ & Reasonable & 8 \\
\hline & $\begin{array}{c}\text { Clock } \\
\text { accuracy }\end{array}$ & $1.6 \times 10^{-7} \mathrm{q}$ & Reasonable & 8 \\
\hline
\end{tabular}
calibrator. The traceable values of components are based on the setup of the standard PD calibrator and calibration technology of general PD calibrators.

Table 6. Standard uncertainties and types and degrees of freedom in the components of the standard PD calibrator

\section{Estimation of uncertainties in the standard PD calibrator}

\subsection{Measurement of charge magnitude and rising time}

The standard PD calibrator was tested with single pulses of various charges and widths. Table 7 shows averages of charges and rising times, their standard deviations, and durations. The ranges of charges were controlled by modules. 
Module A1 generates from 1 to $10 \mathrm{pC}$; Module A2 generates from 10 to $100 \mathrm{pC}$; and Module A3 generates from 50 to 500 $\mathrm{pC}$. The widths of pulses could be adjusted from 10 to $500 \mathrm{~ns}$.

\subsection{Estimation uncertainties of charge magnitude and rising time}

Estimations of the expanded uncertainties of charges and rising times in the standard PD calibrator from Table 7 using (4)-(8) are shown in Table 8. These results show lower uncertainties than those in IEC 60270.

Table 7. The results of charges, rising times, and durations in single pulses

\begin{tabular}{c|c|c|c|c|c|c|c}
\hline \multicolumn{3}{c|}{ Test conditions } & \multicolumn{2}{c|}{ Charge (pC) } & \multicolumn{2}{c|}{$\begin{array}{c}\text { Rising time } \\
\text { (ns) }\end{array}$} & $\begin{array}{c}\text { Dura- } \\
\text { tion } \\
\text { (ns) }\end{array}$ \\
\hline Module & $\begin{array}{c}\text { Charge } \\
(\mathrm{pC})\end{array}$ & $\begin{array}{c}\text { Width } \\
(\mathrm{ns})\end{array}$ & Charge & S.D. & Time & S.D. & \\
\hline $\mathrm{A} 1$ & 1 & 10 & 1.055 & 0.020 & 3.44 & 0.126 & 13.38 \\
\hline $\mathrm{A} 1$ & 2 & 30 & 2.152 & 0.027 & 3.88 & 0.169 & 35.18 \\
\hline $\mathrm{A} 1$ & 5 & 30 & 5.382 & 0.041 & 3.68 & 0.193 & 35.62 \\
\hline $\mathrm{A} 1$ & 10 & 50 & 10.751 & 0.042 & 3.84 & 0.158 & 57.48 \\
\hline $\mathrm{A} 2$ & 10 & 30 & 10.583 & 0.070 & 3.88 & 0.329 & 37.76 \\
\hline $\mathrm{A} 2$ & 20 & 50 & 21.386 & 0.367 & 4.60 & 0.516 & 62.00 \\
\hline $\mathrm{A} 2$ & 50 & 100 & 51.010 & 0.852 & 4.80 & 0.422 & 113.5 \\
\hline $\mathrm{A} 2$ & 100 & 200 & 103.676 & 0.939 & 5.20 & 0.632 & 212.7 \\
\hline $\mathrm{A} 3$ & 100 & 50 & 103.001 & 0.366 & 5.94 & 0.184 & 65.81 \\
\hline $\mathrm{A} 3$ & 200 & 100 & 207.148 & 0.455 & 6.83 & 0.287 & 120.56 \\
\hline $\mathrm{A} 3$ & 500 & 450 & 516.283 & 1.913 & 8.62 & 0.730 & 455.84 \\
\hline
\end{tabular}

Table 8. Uncertainties of charges and rising times in single pulses

\begin{tabular}{c|c|c|c|c|c|c}
\hline \multicolumn{3}{c|}{ Test conditions } & \multicolumn{2}{c|}{$\begin{array}{c}\text { Uncertainty of } \\
\text { charge }\end{array}$} & \multicolumn{2}{c}{$\begin{array}{c}\text { Uncertainty of } \\
\text { rising time }\end{array}$} \\
\hline Module & $\begin{array}{c}\text { Charge } \\
(\mathrm{pC})\end{array}$ & $\begin{array}{c}\text { Width } \\
(\mathrm{ns})\end{array}$ & $\begin{array}{c}\text { Charge } \\
(\mathrm{pC})\end{array}$ & $\%$ & $\begin{array}{c}\text { Time } \\
(\mathrm{ns})\end{array}$ & $\%$ \\
\hline $\mathrm{A} 1$ & 1 & 10 & 0.014 & 1.4 & 0.08 & 2.3 \\
\hline $\mathrm{A} 1$ & 2 & 30 & 0.020 & 1.0 & 0.10 & 2.6 \\
\hline $\mathrm{A} 1$ & 5 & 30 & 0.040 & 0.8 & 0.12 & 3.3 \\
\hline $\mathrm{A} 1$ & 10 & 50 & 0.069 & 0.7 & 0.10 & 2.6 \\
\hline $\mathrm{A} 2$ & 10 & 30 & 0.052 & 0.5 & 0.20 & 5.2 \\
\hline $\mathrm{A} 2$ & 20 & 50 & 0.231 & 1.2 & 0.32 & 7.0 \\
\hline $\mathrm{A} 2$ & 50 & 100 & 0.539 & 1.1 & 0.26 & 5.4 \\
\hline $\mathrm{A} 2$ & 100 & 200 & 0.634 & 0.6 & 0.39 & 7.5 \\
\hline $\mathrm{A} 3$ & 100 & 50 & 0.372 & 0.4 & 0.11 & 1.9 \\
\hline $\mathrm{A} 3$ & 200 & 100 & 0.675 & 0.3 & 0.18 & 2.6 \\
\hline $\mathrm{A} 3$ & 500 & 450 & 1.872 & 0.4 & 0.45 & 5.2 \\
\hline
\end{tabular}

Fig. 6 shows the uncertainties of charges of the standard PD calibrator and limits of IEC 60270 and KERI. In Table 8 , uncertainties of charges in the standard PD calibrator were found to be $0.3 \%-1.4 \%$, and their uncertainties of rising times were found to be $1.9 \%-7.0 \%$

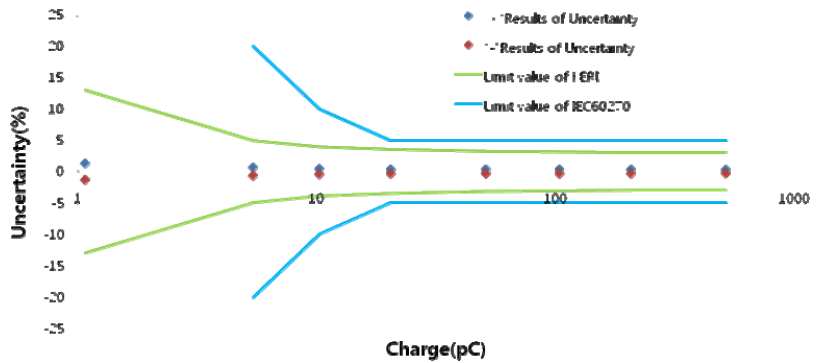

Fig. 6. Relationship between uncertainties of charge and limits of IEC 60270 and KERI

\section{Discussion}

The standard PD calibrator was designed for PICOR; however, it has higher sampling rates and is more easily programmable than PICOR $[5,6]$. Therefore, the proposed standard PD calibrator could generate pulses that have controllable duration time.

The standard PD calibrator pulse generator is able to generate single, double, random, oscillating, and longrising pulses, and control the charges from 0 to $500 \mathrm{pC}$ with capacitor modules. Because the software has the ability to eliminate the error of the human eye and bias of measuring data, the accuracy of charge measurement can be upgraded. Because the developed PD calibrator has traceable components and because analysis technology of its model has been developed, it is appropriate for use as the standard PD calibrator.

Therefore, the standard PD calibrator increases the reliability of PD measurement and can be used as a basis for the estimation of PD uncertainty.

\section{Conclusion}

The standard PD calibrator in KERI is able to generate single, double, random, oscillating, and long-rising pulses. It has low uncertainties of charges and rising times. In single pulses, uncertainties of charges were found to be $0.3 \%-1.4 \%$, and uncertainties of rising time were found to be $1.9 \%-7.0 \%$. Uncertainties of charges and rising times in the standard PD calibrator were measured as less than the limits of IEC 60270 and KERI. The standard PD calibrator is the first fully programmable system to generate pulses and calculate charges and rising times from measuring data. The use of technology to eliminate the errors of the human eye and offset voltages included in the measuring data has upgraded the presented calibration technology.

Therefore, the standard PD calibrator could be used for calibrating general PD calibrators and PD detectors used by electric companies. Moreover, the developed standard PD calibrator could be used as the basis of the future development of PD technologies. 


\section{References}

[1] International Electrotechnical Commission, "Partial Discharge Measurement", IEC 60270, First edition, 1968.

[2] International Electrotechnical Commission, "Partial Discharge Measurement", IEC 60270, Second edition, 1981.

[3] International Electrotechnical Commission, "Partial Discharge Measurement", IEC 60270, Third edition, Dec., 2000.

[4] G. Zinglaes, "Present State and Prospects of Standardization on PD Measurement", IEEE Trans. on Electrical Insulation Vol. 28 No. 6, December 1993, pp. 902-904.

[5] K. Schon, W. Lucas, "Intercomparison of Impulse charge Measurement" European Commission Standards, Measurements and Testing Programme Project SMT4-CT95-7501, 1998.

[6] K. Schon, H. D. Valentini, "Programmable Impulse Charge Generator for Calibrating PD Instrument", in 10th International Symposium on High Voltage Engineering, 1997.

[7] Walter S. Zaengel and Kurt Lehmann, "A Critique of Present Calibration Procedure for Partial Discharge Measurement", , IEEE Trans. on Electrical Insulation Vol. 28 No. 6, December 1993, pp. 1043-1049.

[8] G. Zinglaes, "The Requirements of a PD Measuring System Analyzed in the Time Domain", IEEE Trans. On Dielectric and Electrical Insulation Vol. 7 No. 1, February 2000, pp. 2-5.

[9] P. Osvath, E. Carminati and A. Gandelli, "A contribution on the traceability of partial discharge measurements", IEEE Trans. on Electrical Insulation Vol. 27 No. 1, February 1992, pp. 130-134

[10] Robin E. Bently, "Uncertainty in Measurement: the ISO Guide", National Measurement Laboratory CSIRO, TIP P1337, July. 2003.

[11] Agilent Technologies, "Certificate of Calibration, Certificate", No. 81150ADE47C00362, Jun. 12, 2008.

[12] Tektronix, "Certificate of Traceable Calibration", Certificate No. PBXPNLJ6JW, Sep. 2, 2008.

[13] Murata Manufacturing Co., "Chip Monolithic Ceramic Capacitor-High Frequency", GQM Series Data Sheet, Sep. 1,08.

[14] Nikkohm Co., "Disk Resistor", Data Sheet, 2008.

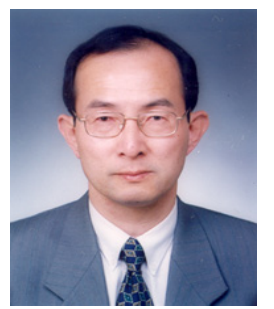

Kwang-Hwa Kim received his B.S., M.S., and Ph.D. degrees in Electrical Engineering from Pusan University, Pusan, Korea, in 1981, 1983, and 1992, respectively. Currently, he is a Principal Researcher at the Korea Electrotechnology Research Institute (KERI) in Korea. He has studied the measurement of partial discharge. His research interests include the diagnosis of power facilities, high-voltage engineering, and its applications.

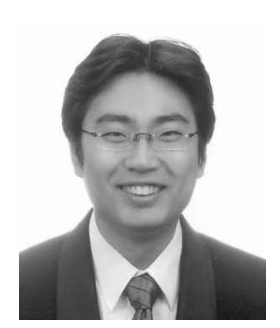

Sang-Hwa Yi received his B.S. degree in Electronic Engineering from Korea University, Seoul, Korea, in 2001, and M.S. degree in Microwave Engineering from Pohang University of Science and Technology (POSTECH) in 2003. Since joining KERI in 2003, he has been active in developing online PD diagnosing systems, including UHF sensors for GIS, transformers, and rotating machines. His research interests include diagnosis of power facilities using microwave engineering.

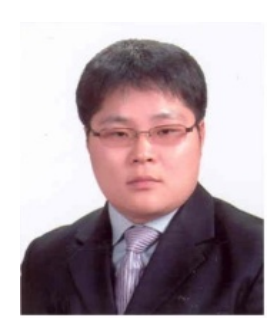

Heun-Jin Lee received his B.S. degree in Computer Technology from Kyungnam University, Changwon, Korea, in 2004. He is currently a researcher at the Power Apparatus Research Center, KERI, Changwon, Korea. His research interests include condition monitoring for GIS and

transformers.

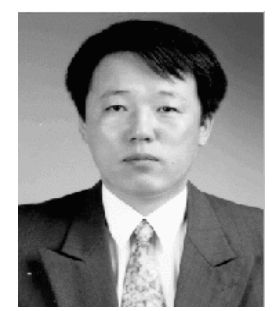

Dong-Sik Kang received his B.S., M.S., and Ph.D. degrees in Electrical Engineering from Pusan National University, Pusan, Korea, in 1983, 1992, and 2002, respectively. Since joining the Research Division of KERI in 1987, he has been active in developing the online diagnostic techniques for power facility (rotating machines, transformers, and cables). His main concern is to develop partial-discharge detection techniques (sensor, detection system, and noise cancellation method). Currently, he is Director of the Power Facility Diagnosis Research Center in KERI. 